\title{
Effect of Temperature on Interesterification of Rapeseed Oil with Methyl Acetate in Presence of BuOK/BuOH
}

\author{
Valdis Kampars $^{1}{ }^{*}$, Reinis Gravins ${ }^{1}$, Kristine Lazdovica ${ }^{1}$, and Ruta Kampare ${ }^{1}$ \\ ${ }^{1}$ Institute of Applied Chemistry, Riga Technical University, P. Valdena Str. 3/7, Riga, LV-1048, Latvia
}

\begin{abstract}
If the interesterification reaction of rapeseed oil with methyl acetate at reactant to oil molar ratio of 18:1 in presence of potassium tert-butoxide in tert-butanol of molar ratio to oil 0.08 is conducted at a temperature of about $35^{\circ} \mathrm{C}$, reaction time for full conversion of oil is shorter than one hour, while at a temperature of $55^{\circ} \mathrm{C}$ it is approximately 15 minutes. Reaction time at the desired temperature has a wide "optimal" range and cannot be an effective variable for the process optimisation. Experimental results at the temperature of $25^{\circ} \mathrm{C}$ confirm the pseudo-first order of the reaction, which lowered towards the end of the reaction. The pseudo-first order rate constant was $0.63 \mathrm{~min}^{-1}$. Fuel characteristics of the interesterification reaction mixtures without purification improved with the rising of reaction temperature from $35^{\circ} \mathrm{C}$ to $55^{\circ} \mathrm{C}$, however, they fail to meet the requirements of standard EN14214 for biodiesel. Methyl acetate to oil molar ratio 18:1 is too low for obtaining products with kinematic viscosity below $5.0 \mathrm{~mm}^{2} / \mathrm{s}$.
\end{abstract}

\section{Introduction}

Almost $95 \%$ of the world's transportation energy come from petroleum-based fuels, largely gasoline and diesel. A growing energy demand in the transport sector gives rise to emissions of carbon dioxide and facilitates global warming. On the other hand, a lack of a simple technology and resources for unrestricted production of biofuels today continue to secure the economic advantage of the petroleum-based fuels, and a vital interest in biofuels can only be observed from time to time. The most produced and used biofuel in Europe is biodiesel. Biodiesel is one of the good alternatives to the conventional energy resources. It is well known as a renewable, nontoxic, aromatic and sulphur-free, biodegradable, and environment-friendly fuel that can perfectly substitute petrodiesel. Biodiesel usually consists of fatty acid methyl esters (FAME) and can be produced from different sources of lipids: vegetable edible and non-edible oils, animal fats, algae, and waste oils [1, 2]. Currently biodiesel in Europe is produced mainly from rapeseed oil. Biodiesel from edible vegetable oils belongs to the first generation biofuels, and its production is restricted by food versus fuel pressures [3]. As a result of restricted raw materials, the EU still remains the world's largest biodiesel producer, but nearly two-thirds of the region's installed production capacity is currently idle [4]. The development of second generation biodiesel, which is aimed at most sustainable feedstock, or elaboration of a new technology for the existing production is critical to the biofuel production, as conversion of lignocellulose biomass to fuel involves many unsolved technical difficulties. Conventionally the biodiesel production proceeds by transesterification of triglycerides with methanol in the presence of basic catalyst. This technology yields glycerol as a by-product and is sensitive to free fatty acids (FFA) present in the feedstock [5]. These disadvantages of transesterification encouraged a search for a more effective process for the synthesis of biodiesel with full conversion of raw material to fuel. Such process could be interesterification.

In interesterification reaction with methyl acetate (1) the same composition of FAME as in transesterification with methanol (2) has to be synthesised, but another byproduct is formed:

(1), $\mathrm{TG}+3 \mathrm{MeAc} \rightleftarrows 3 \mathrm{FAME}+\mathrm{TA}$,

where TG - triglycerides, MeAc - methyl acetate, FAME - mixture of fatty acid methyl esters, TA triacetin.

(2), $\mathrm{TG}+3 \mathrm{MeOH} \rightleftarrows 3 \mathrm{FAME}+\mathrm{G}$,

where $\mathrm{MeOH}$ - methanol, G - glycerol.

TA is compatible with FAME and can be included into biofuel composition, thus ensuring full conversion of oil to biofuel [6-9]. Interesterification reactions, as well as transesterification one proceeds under supercritical conditions or in presence of catalysts. Supercritical and enzymatic methods of interesterification have their own advantages and disadvantages, but they are not so productive as the

* Corresponding author: Valdis.Kampars@,rtu.lv 
chemical ones. Casas et al. have shown that the most active chemical catalysts are alkali metal alkoxides [10], while such active transesterification catalysts as alkali metal hydroxides are, surprisingly, inactive. The alkali metal alkoxide catalyst used most commonly is sodium methoxide in methanol, but if the alkali metal alkoxide is dissolved in alcohol (excluding tert-butanol), interesterification reaction with solvent proceeds as a parallel reaction [11]. In our previous research we have shown that tert-BuOK/tert-BuOH catalyst [12] has high activity and is very suitable for interesterification reactions without competing transesterifications, therefore this catalyst has been used in this work to investigate kinetics of the interesterification of rapeseed oil with methyl acetate.

\section{Experimental section}

\subsection{Material}

The refined rapeseed oil was purchased from the local producer Iecavnieks. Average molecular weight of oil was $896 \mathrm{Da}, \mathrm{HHV} 39.860 \mathrm{MJ} / \mathrm{kg}$, density $0.92 \mathrm{~g} / \mathrm{ml}$ at $20{ }^{\circ} \mathrm{C}$, element composition $\mathrm{C} 77.736 \%$ and $\mathrm{H} 11.551 \%$ and $\mathrm{O} 10.713 \%$, saponification value 186.7 and acid value $0.32 \mathrm{mgKOH} / \mathrm{g}$. Percentage of fatty acids of the oil: palmitic 4; stearic 2; oleic 64; linoleic 22 and linolenic 8 . The methyl acetate $(99 \%)$, phosphoric acid $(85 \%)$ and potassium tert-butoxide $1 \mathrm{M}$ solution in THF were obtained from Sigma-Aldrich. Materials for GC analysis - methyl heptadecanoate $(95 \%)$ was purchased from Sigma-Aldrich, 1,2,4-butanetriol (96\%) and MSTFA (N-methyl-N-(trimethylsilyl) trifluoroacetamide, $97 \%$ ) - from Alfa Aesar, tricaprin (> $98 \%$ ) - from TCI Europe, heptane (> 95\%), and dichloromethane (pure) from ROTH.

\section{$2.2 \quad$ Experimental interesterification}

procedure of

The rapeseed oil and methyl acetate were mixed and heated up to the desired temperature in the $250-\mathrm{mL} \mathrm{3-}$ neck round bottom flask, equipped with a reflux condenser, thermometer and magnetic stirrer-heater. The rotational speed was set at $800 \mathrm{rpm}$. Then catalyst was added to the agitated reactor and the reaction time was started. Samples were collected after 1, 2, 3, 6, 10, 20, $30,40,60,80,100$ and $120 \mathrm{~min}$ and immediately quenched with an equimolar amount of phosphoric acid to remove the catalyst. Then after removing the excess of methyl acetate by rotary evaporation and the potassium phosphate by filtration, samples were stored in refrigerator until analysis. The concentration of catalyst was measured in molar ratio to oil $(\mathrm{COMR}=0.08)$ and the concentration of methyl acetate in molar ratio of MeAc to oil $($ MAOMR $=18)$.

\subsection{Analytical methods}

Average molecular mass of rapeseed oil was calculated from saponification value according to the following ration: average molecular mass $=$ mass of oil $/$ number of moles of base. Saponification value was determined according to the ASTM D5558 and acid value -according to the EN 14104 standard. The elemental analysis was carried out on a EuroEA Elemental Analyser. The analysis of all components of each sample of interesterification products was carried out by using an Analytical Controls biodiesel analyser based on Agilent Technologies gas chromatograph 7890A, equipped with 2 columns. Ester content was determined according to the modified standard method EN 14103, using a methyl heptadecanoate as an internal standard. The capillary column employed was a HP Innowax with a length of $30 \mathrm{~m}$, an internal diameter of $0.25 \mathrm{~mm}$ and a film thickness of $0.25 \mu \mathrm{m}$. Oven temperature was set at $200{ }^{\circ} \mathrm{C}$. Glycerol, mono-(MG), di- (DG) and TG, diacetyl monoglycerides (DAMG), monoacetyl diglycerides (MADG), monoacetyl monoglycerides (MAMG), monoacetin (MA), diacetines (DA), TA and FAME were analysed using DB5-HT column (15 m, $0.32 \mathrm{~mm}, 0.10 \mu \mathrm{m})$ under conditions prescribed in standard EN 14105, and mass percentage of reaction mixture was calculated as specified in our previous work [7]. The oven temperature was set to $50{ }^{\circ} \mathrm{C}$ for $5 \mathrm{~min}$ and then it was increased to $180^{\circ} \mathrm{C}$ at the rate of $15^{\circ} \mathrm{C} / \mathrm{min}$, then to $230^{\circ} \mathrm{C}$ at the rate of $7{ }^{\circ} \mathrm{C} / \mathrm{min}$ and finally to $370{ }^{\circ} \mathrm{C}$ at the rate of $10^{\circ} \mathrm{C} / \mathrm{min}$. Helium was used as a carrier gas, and detector temperature was set $390{ }^{\circ} \mathrm{C}$ in both methods. Chromatographic analysis of each sample was performed three times and the arithmetical average as characteristic were used. Deviation of measurement within a $95 \%$ confidence interval for the FAME was \pm $1 \%$ and for $\mathrm{TA} \pm 0.3 \%$.

Density of fuel $\left(15^{\circ} \mathrm{C}\right)$ was determined with the use of Anton Paar DMA 4500 density meter according to the standard method EN ISO 12185. Kinematic viscosity (40 ${ }^{\circ} \mathrm{C}$ ) was determined with the use of Anton Paar SVM 3000 viscosity meter according to the standard method EN ISO 3104. The measurements of cold filter plugging point (CFPP) were performed on the basis of DIN EN 116 standard method with the use of ISL FPP 5Gs equipment. Carbon residue was determined with the use of Alcor MCRT-160 tester according to the standard method ASTM D 4530 without any previous treatment of reaction mixture. Each measurement was made in doubles and the average value was calculated.

\section{Results and discussion}

\subsection{Composition of reaction mixtures and reaction kinetics}

As can be seen from Table 1 below, the increase of temperature from 25 to $55{ }^{\circ} \mathrm{C}$ remarkably influenced the proceeding of interesterification of rapeseed oil with methyl acetate under fixed COMR and MAOMR. The equilibrium of interesterification reaction at the temperature of $25{ }^{\circ} \mathrm{C}$ was reached after approximately $80-120 \mathrm{~min}$ but at the temperature of $55^{\circ} \mathrm{C}-$ after $10-$ $20 \mathrm{~min}$. The equilibrium compositions of reaction 
mixtures obtained at various reaction temperatures were slightly different.

It may be observed that the reaction time at a constant reaction temperature had some "critical" value, after that the product content remained approximately constant. At the temperature of $25^{\circ} \mathrm{C}$ such plateau proceeds from 50 to $120 \mathrm{~min}$, at $35^{\circ} \mathrm{C}$ - from 20 to $80 \mathrm{~min}$, at $45^{\circ} \mathrm{C}$ - from 10 to $60 \mathrm{~min}$, and at $55^{\circ} \mathrm{C}-$ from 10 to $40 \mathrm{~min}$. Thus, reaction time at the defined temperature and low COMR values have a relatively wide near to the optimal range. According to Table 1, it is problematic to precisely determine the end of the regular change of component concentration, but determination of the most feasible intervals for them gives $10-20,30-40,40-60$ and $80-120 \mathrm{~min}$ for the reactions at 55, 45, 35 and $25{ }^{\circ} \mathrm{C}$ respectively. Assuming that the middle points of these intervals represented the equilibrium mixture and using the characteristics at 15 , 35,50 and 100 min respectively, it may be concluded that the concentration of the target product TA immediately after reaching the plateau achieves a maximum at $35{ }^{\circ} \mathrm{C}$, but the slow increase of FAME proceeds to $55^{\circ} \mathrm{C}$ (Fig. 1).

Table 1. Composition (MG, MAMG, DAMG, DG, MADG, TG, DA, TA and FAME) change over time at the temperatures of $25,35,45$ and $55^{\circ} \mathrm{C}$

\begin{tabular}{|c|c|c|c|c|c|c|c|c|c|}
\hline Time, min & MG & MAMG & DAMG & DG & MADG & TG & DA & TA & FAME \\
\hline $\begin{array}{c}25^{\circ} \mathrm{C} \\
1\end{array}$ & 0.4 & 1.1 & 3.5 & 4.0 & 19.1 & 51.7 & 0.2 & 0.1 & 20.2 \\
\hline 2 & 0.5 & 1.3 & 2.5 & 3.9 & 21.6 & 35.3 & 0.3 & 1.0 & 28.2 \\
\hline 3 & 0.7 & 1.1 & 9.9 & 2.9 & 21.7 & 13.5 & 0.4 & 2.7 & 41.0 \\
\hline 6 & 0.9 & 1.1 & 11.2 & 2.3 & 18.8 & 8.4 & 0.5 & 3.8 & 46.9 \\
\hline 10 & 1.0 & 1.2 & 11.6 & 2.0 & 16.0 & 5.9 & 0.6 & 4.5 & 50.4 \\
\hline 20 & 1.0 & 1.2 & 12.1 & 1.4 & 12.3 & 3.3 & 0.7 & 6.6 & 55.8 \\
\hline 30 & 1.1 & 1.0 & 11.8 & 1.2 & 10.8 & 2.6 & 0.7 & 6.8 & 57.8 \\
\hline 40 & 1.2 & 1.1 & 11.7 & 1.1 & 9.9 & 2.3 & 0.9 & 7.5 & 58.9 \\
\hline 60 & 1.1 & 1.1 & 11.6 & 1.1 & 9.2 & 2.0 & 0.9 & 7.8 & 60.1 \\
\hline 80 & 1.2 & 1.1 & 11.5 & 1.0 & 8.8 & 1.9 & 1.0 & 7.9 & 61.0 \\
\hline 100 & 1.3 & 1.2 & 11.7 & 1.0 & 8.7 & 2.0 & 1.0 & 8.0 & 61.0 \\
\hline 120 & 1.1 & 1.3 & 11.5 & 1.1 & 8.8 & 2.0 & 1.0 & 8.4 & 61.0 \\
\hline $\begin{array}{c}35^{\circ} \mathrm{C} \\
1\end{array}$ & 0.9 & 1.2 & 11.3 & 1.4 & 11.2 & 7.2 & 0.7 & 7.5 & 52.1 \\
\hline 2 & 1.0 & 1.0 & 9.4 & 0.7 & 5.8 & 1.6 & 0.8 & 10.2 & 62.7 \\
\hline 3 & 1.0 & 1.0 & 8.7 & 0.3 & 3.0 & 0.0 & 1.3 & 11.7 & 64.6 \\
\hline 6 & 1.0 & 1.1 & 8.3 & 0.2 & 2.5 & 0.0 & 1.5 & 11.6 & 68.1 \\
\hline 10 & 1.1 & 1.2 & 8.1 & 0.1 & 2.0 & 0.0 & 1.7 & 11.2 & 69.4 \\
\hline 20 & 1.2 & 1.5 & 8.2 & 0.1 & 2.2 & 0.0 & 1.7 & 11.1 & 69.7 \\
\hline 30 & 1.2 & 1.5 & 8.1 & 0.2 & 2.3 & 0.0 & 1.9 & 11.2 & 70.1 \\
\hline 40 & 1.3 & 1.7 & 8.1 & 0.1 & 2.2 & 0.0 & 2.0 & 11.1 & 70.1 \\
\hline 60 & 1.2 & 1.4 & 8.3 & 0.1 & 2.3 & 0.0 & 2.0 & 10.6 & 70.2 \\
\hline $\begin{array}{c}45^{\circ} \mathrm{C} \\
3\end{array}$ & 0.6 & 0.9 & 9.5 & 0.4 & 4.1 & 0.0 & 1.0 & 10.6 & 66.6 \\
\hline 6 & 1.1 & 1.0 & 8.9 & 0.2 & 2.8 & 0.0 & 1.3 & 10.3 & 68.3 \\
\hline 10 & 1.1 & 1.1 & 8.6 & 0.0 & 2.3 & 0.0 & 1.6 & 10.2 & 68.2 \\
\hline 20 & 1.2 & 1.2 & 8.3 & 0.0 & 2.0 & 0.0 & 1.5 & 10.1 & 69.8 \\
\hline 30 & 1.3 & 1.4 & 8.5 & 0.0 & 1.8 & 0.0 & 1.7 & 10.2 & 70.3 \\
\hline 40 & 1.2 & 1.4 & 8.7 & 0.0 & 1.9 & 0.0 & 1.9 & 10.3 & 70.4 \\
\hline $\begin{array}{c}55^{\circ} \mathrm{C} \\
3\end{array}$ & 1.1 & 1.3 & 7.5 & 0.2 & 2.2 & 0.0 & 2.4 & 10.0 & 66.9 \\
\hline 6 & 1.3 & 1.6 & 7.8 & 0.3 & 1.6 & 0.0 & 1.8 & 9.5 & 70.0 \\
\hline 10 & 1.3 & 1.8 & 7.6 & 0.3 & 1.5 & 0.0 & 2.1 & 9.3 & 70.0 \\
\hline 20 & 1.3 & 1.8 & 7.3 & 0.3 & 1.8 & 0.0 & 3.0 & 9.3 & 70.2 \\
\hline 30 & 1.3 & 2.0 & 7.6 & 0.3 & 2.4 & 0.0 & 2.8 & 9.3 & 70.5 \\
\hline
\end{tabular}

*Information about $\mathrm{G}$ and MA are not included, as the values are near to zero

The local maximum on a graph of the target product TA curve has not been discussed in the literature because the temperature profiles of interesterification reactions have not been investigated in detail so far [13], it is, however, known that the FAME content in reaction mixtures usually increases with the increasing of temperature $[9,13]$. It is also known that an increase of another variable, i.e. reaction time, causes different variation of FAME and TA content: with the increasing of reaction time, the content of FAME increases, while the content of TA reaches maxima and then decreases [14]. The various influence of the temperature on FAME and TA content in the interesterification referred to in this work could be similar to the influence of reaction time, and therefore it seems to be very feasible. It has been shown that the raising of temperature in transesterification reactions cannot increase the FAME content in all cases [15] and also can occur in some 
reactions with maxima for all variables [1]. In all cases such result could be explained by the influence of different side reactions, proceeding in the presence of catalyst as competing for the desired ones.

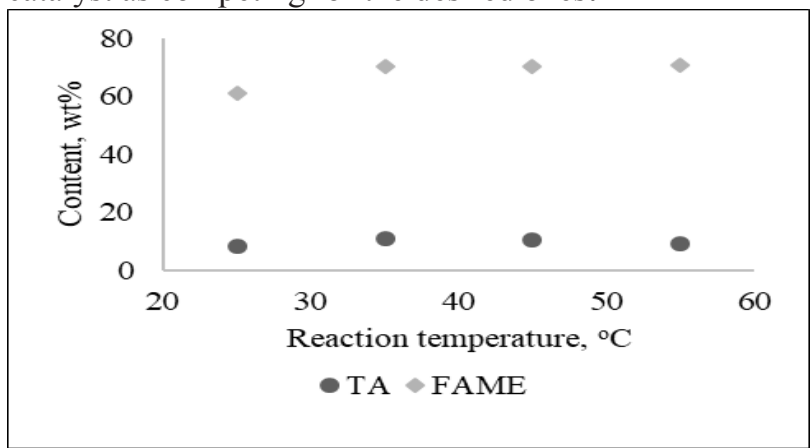

Fig. 1. Content of target products after reaching equilibrium at different temperatures

The highest concentration of intermediates in the form of triesters of MADG and DAMG contains the equilibrium mixture at the temperature of $25^{\circ} \mathrm{C}$. This reaction mixture is the only one which also contains a small amount of oil. When increasing a reaction temperature, TG undergoes full, while MADG and DAMG only particular conversion to the target products and other intermediates - glycerol derivatives with hydroxyl groups (MG, DG, MAMG and DAG). The last intermediates are products of hydrolysis with water present in TG and MA, and products of catalyst quenching by reaction with $85 \%$ phosphoric acid at the end of interesterification. As can be seen in Fig. 2, the reactions at the temperatures of 35 and $45^{\circ} \mathrm{C}$ provide a possibility to obtain reaction mixtures with the lowest content of intermediates. The content of glycerol derivatives with free hydroxyl group has a tendency to rise at a temperature higher than $45^{\circ} \mathrm{C}$. The content of MG which, according to the standard EN14214, is exactly critical to cold flow properties of FAME being used as a blend component for diesel fuel [16], is not influenced by a reaction temperature within a range of $25-45{ }^{\circ} \mathrm{C}$.

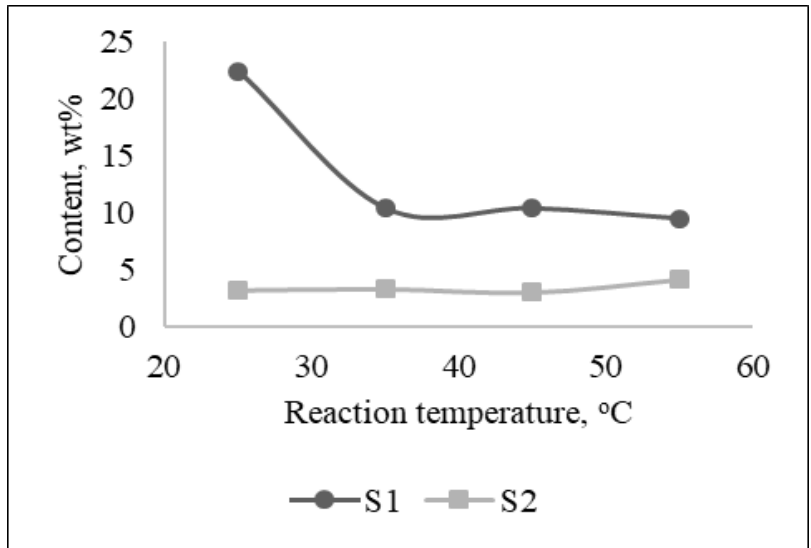

Fig. 2. Content of intermediates: glycerol triesters $(\mathrm{S} 1=\mathrm{TG}+$ $\mathrm{MADG}+\mathrm{DAMG})$ and glycerol di- and monoesters (S2 = DG + $\mathrm{MG}+\mathrm{DAG}+\mathrm{MAG}$ ) after reaching the equilibrium at different reaction temperatures.
According to Table 1, only reaction at the temperature of $25{ }^{\circ} \mathrm{C}$ is appropriate for the investigation of kinetics using traditional methods of product sampling. The obtained results show (Fig. 3.) that, apart from small irregularities, the majority of experimental points fit the theoretical first order equation with the half - live $\tau_{1 / 2}=$ $1.1 \mathrm{~min}$. It is also clear that at the end of reaction the order of reaction changes. Earlier for the transesterification reaction it has been shown [17] that the reaction rate at the end of the reaction was reduced to the zero order.

It is known from literature that different kinetic models have been used for the interpretation of experimental results. The model of Casas et al. [18] was based on the stepwise proceeding of the reaction (1) and different side reactions caused by the presence of methanol as a catalyst solvent (transesterification of interesterification intermediates, interesterification of transesterification intermediates and trans- and interesterification reactions of MAMG). Using mathematical processing of experimental data, the authors have obtained values of 15 different pseudoconstants.

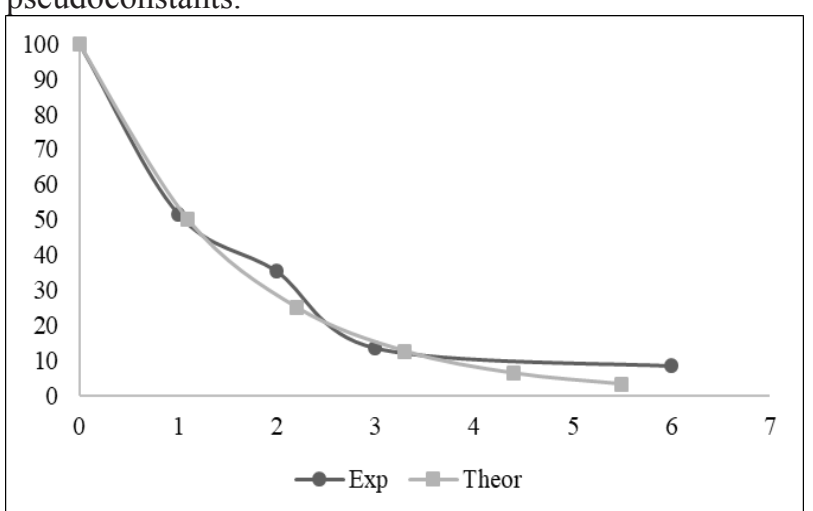

Fig.3. Experimental (at $25{ }^{\circ} \mathrm{C}$ ) and theoretical (first order reaction with $\tau_{1 / 2}=1.1 \mathrm{~min}$ ) variations of $\mathrm{TG}$ content over time.

The general equation (3)

$$
-\mathrm{d}[\mathrm{TG}] / \mathrm{d} t=\mathrm{k} *[\mathrm{TG}]^{\alpha} *[\mathrm{MA}]^{\beta}
$$

has been analysed further below, considering that in the presence of large excess of reactant the reaction formally proceeds irreversible, because at the end of reaction concentration of TG is zero. If MA is present in excess, its concentration remains virtually constant during the course of the reaction. Thus, the $\mathrm{TG}$ is the limiting reactant, and the rate of reaction obtains the form of pseudo-first order $[17,19,20]$ what have been confirmed by experiments for transesterification reactions.

We have obtained in our investigation $\tau_{1 / 2}=1.1 \mathrm{~min}$ which can be used for obtaining the pseudo-first order rate constant $\mathrm{k}=0,693 / \tau_{1 / 2}=0.63 \mathrm{~min}^{-1}$. Using only the experimental points at $3,6,10$ and $20 \mathrm{~min}$ the pseudofirst order constant can also be obtained; however, its value is approximately 8 times lower. This means that the slow reduction of formally first order kinetics proceeds earlier than anticipated, and it is necessary to use experimental data for the first $\tau_{1 / 2}$ in order to determine the true reaction constant. 
For the quantitative comparison of catalysts Arrhenius activation energy is more appropriate than the rate constant, therefore the next step is the elaboration of the method for the activation energy determination.

\subsection{Fuel characteristics}

Testing of the obtained reaction mixtures without any purification according to the standard EN 14214 for biodiesel shows (Table 2) that without FAME content, intermediates and density all other characteristics are close to the requirements of the standard despite the complicated composition. As can be seen from Table 2, reaction mixture $\mathrm{Th}$ with stoichiometry of products according to reaction (1) also cannot comply with the density requirement, whereas pure FAME from the same oil fulfil them excellently.

Table 2. Fuel characteristics of the obtained reaction mixtures.

\begin{tabular}{|c|c|c|c|c|c|c|c|}
\hline \multirow[b]{2}{*}{ Sample } & \multicolumn{7}{|c|}{ Characteristics } \\
\hline & $\begin{array}{l}\text { Flash point, } \\
{ }^{\circ} \mathrm{C}\end{array}$ & $\begin{array}{c}\text { Density, } \\
\mathrm{kg} / \mathrm{m}^{3}\end{array}$ & $\begin{array}{l}\text { Viscosity } \\
\mathrm{mm}^{2} / \mathrm{s}\end{array}$ & $\begin{array}{c}\text { Carbon } \\
\text { residue, } \\
\%\end{array}$ & $\begin{array}{l}\mathbf{C P}, \\
{ }^{\circ} \mathrm{C}\end{array}$ & $\begin{array}{c}\text { CFPP, } \\
{ }^{\circ} \mathrm{C}\end{array}$ & $\begin{array}{c}\text { PP, } \\
{ }^{\circ} \mathrm{C}\end{array}$ \\
\hline $\begin{array}{c}\text { EN14214 } \\
\text { limits }\end{array}$ & 101 & 900 & 5.0 & & & & \\
\hline TG & 285 & 910 & 34.1 & 0.3 & & & \\
\hline FAME & $>200$ & 882 & 4.0861 & $<0.01$ & -12 & -10 & -13 \\
\hline $\mathrm{Th}^{*}$ & $>150$ & 922.8 & 4.1176 & $<0.01$ & -11 & -11 & -14 \\
\hline $25^{\circ} \mathrm{C}$ & $>150$ & 923.4 & 5.3795 & 0.091 & -9 & -7 & -9 \\
\hline $35^{\circ} \mathrm{C}$ & $>150$ & 923.0 & 5.0185 & 0.11 & -9 & -9 & -9 \\
\hline $45^{\circ} \mathrm{C}$ & $>150$ & 921.5 & 5.0569 & 0.11 & -8 & -9 & -9 \\
\hline $55^{\circ} \mathrm{C}$ & $>150$ & 923.0 & 5.1032 & 0.086 & -7 & -7 & -10 \\
\hline
\end{tabular}

Th* - artificial mixture of FAME 80.6 and TA 19.4 mass \% respectively.

Kinematic viscosity of all the obtained reaction mixtures was slightly higher than $5.0 \mathrm{~mm}^{2} / \mathrm{s}$ and increases with the lowering of reaction temperature below $35{ }^{\circ} \mathrm{C}$. MAOMR 18 is insufficient for obtaining interesterification reaction mixtures with kinematic viscosity below $5.0 \mathrm{~mm}^{2} / \mathrm{s}$. Reactions at the temperatures of $35{ }^{\circ} \mathrm{C}$ and $45{ }^{\circ} \mathrm{C}$ fail to improve the fuel characteristics in comparison with the reaction at $55^{\circ} \mathrm{C}$.

\section{Conclusions}

Time taken to reach chemical equilibrium of the interesterification reaction of rapeseed oil with methyl acetate in presence of potassium tert-butoxide in tertbutanol (reactant to oil molar ratio 18:1 and catalyst to oil molar ratio 0.08 ) at the temperature of about $35^{\circ} \mathrm{C}$ is remarkably lower than one hour, while at the temperature of $55^{\circ} \mathrm{C}$ it is approximately 15 minutes. Reaction time at the desired temperature has a wide optimal range and cannot serve as an effective variable for the process optimisation. Experimental data at the temperature of $25^{\circ} \mathrm{C}$ confirm the pseudo-first order of the reaction. In order to determine the true pseudo-first rate constant, experimental point for the first $\tau_{1 / 2}$ are required.

Fuel characteristics of the interesterification reaction mixtures improved within a temperature range of $35^{\circ} \mathrm{C}$ to $55^{\circ} \mathrm{C}$, however they fail to meet the requirements of standard EN14214 for biodiesel. Methyl acetate to oil molar ratio 18:1 is too low for obtaining products with kinematic viscosity below $5.0 \mathrm{~mm}^{2} / \mathrm{s}$.

\section{Acknowledgements}

The authors gratefully acknowledge the financial support from the Programme 1.1.1.1/16/A/078 "Synthesis of biodiesel via interesterification of rapeseed oil".

\section{References}

1. G. Baskar, I. Aberna Ebenezer Selvakumari, R. Aiswarya, Bioresour. Technol., 250, 793 (2018)

2. M. Yadav, Y.C. Sharma, J Clean. Prod., 199, 593 (2018)

3. K. Araújo, D. Mahajan, R. Kerr, M. da Silva, Agric., 7, 1 (2017)

4. http://www.biodieselmagazine.com/articles/4447/glo bal-biodiesel-production-and-market-report

5. J.S. Ribeiro, D. Celante, S.S. Simõe, M.M. Bassac, C. Silva, F. Castilhos, Fuel, 200, 499 (2017)

6. A. Casas, J.R. Ruiz, M.J. Ramos, Energy Fuels, 24, 4481 (2010)

7. G.L. Maddikeri, A.B. Pandit, P.R. Gogate, Fuel Process. Technol., 116, 241 (2013)

8. Z. Sustere, V. Kampars, IJETR, 3, 226 (2015)

9. Z. Sustere, R. Murnieks, V. Kampars, Fuel Process. Technol., 149, 320 (2016)

10. A.Casas, M.J.Ramos, A.Perez. Biomass Bioenergy, 35, 1702 (2011)

11. E.Sile, V.Kampars. Proceedings of SGEM, 4.1, 767 (2018)

12. V.Kampars, Z.Sustere, R.Kampare. Proceedings of SGEM, 4.1, 163 (2018)

13. A.Casas, M.J.Ramos, A.Perez. 6, 144 (2013), ISBN: 978-1-62808-565-5

14. V. Kampars, Z. Šustere, R. Kampare, Proceedings of SGEM, 4.1, 18 (2018) 
15. S.D. Jadhav, M.S. Tandale, Environ. Prog. Sustain. Energy, 37, 533 (2018)

16. EN 14214:2012+A1:2014

17. M.A. Olutoyea, B.H. Hameed, J. Taibah Univ. Sci, 10, 685 (2016)

18. A. Casas, M.J. Ramos, I. Perez, Chem. Eng. J., 171, 1324 (2011)
19. M.R. Avhad, M. Sánchez, A. Bouaid, M. Martínez, J. Aracil, J.M. Marchetti, Energy Convers. Manag., 126, 1168 (2016)

20. M.E. Bambase, J.N. Nakamura, J. Tanaka, M. Matsumura, J. Chem. Technol. Biotechnol. 82, 273 (2007) 